\title{
Job Search, Conditional Treatment and Recidivism: The Employment Services for Ex-Offenders Program Reconsidered
}

\author{
Herman J. Bierens* \\ Department of Economics, Pennsylvania State University \\ José R. Carvalho ${ }^{\dagger}$ \\ CAEN, Universidade Federal do Ceará, Brazil.
}

October 29, 2007

\begin{abstract}
The objective of this paper is to re-evaluate the effect of the 1985 "Employment Services for Ex-Offenders" (ESEO) program on recidivism, in San Diego, Chicago and Boston. The initial group of program participants was split randomly in a control group and a treatment group. The actual treatment (mainly being job related counseling) only takes place conditional on finding a job, and not having been arrested, for those selected in the treatment group. We use interval-censored proportional hazard models for job search and recidivism time, where the latter model incorporates the conditional treatment effect, depending on covariates. We find that the effect of the program depends on location and age. The ESEO program reduces the risk of recidivism only for ex-inmates over the age of 27 in San Diego and Chicago, and over the age of 36 in Boston, but increases the risk of recidivism for the other ex-inmates in the treatment group.
\end{abstract}

*Correspondence address: Herman J. Bierens, Department of Economics, Pennsylvania State University, 608 Kern Graduate Building, University Park, PA 16802. E-mail: hbierens@psu.edu.

$\dagger^{T}$ The financial support of CAPES Foundation, Brazil, is gratefully acknowledged. E-mail: josecarv@ufc.br 
Key words: Job search, Recidivism, Conditional treatment, Program evaluation, Duration models, Interval-censoring.

\section{Introduction}

Accordingly to Bloom (2006), more than 600,000 people are released from prison each year in the United States. By any standards this fact raises many concerns about the likely consequences, both social and economic, of such a massive influx of ex-convicts into society. A prominent issue nowadays is the high rates of recidivism prevalent in the country, despite the huge efforts by public authorities to make sure that the rehabilitative role of prisons works properly. In fact, recidivism rates measured by the Bureau of Justice Statistics (1994) show that two-third of released prisoners are re-arrested and one-half are re-incarcerated within three years after release. After a decade from release, Freeman (2003) asserts that, after a decade from release, up to $80 \%$ of prisoners are re-arrested.

Most ex-offenders have low educational levels, medical problems, less work experience than non-offenders. Therefore, the prospects of ex-offenders in the job market are almost always worse than for non-offenders with comparable characteristics (Freeman 1999 and Western 2002), although this is also true before incarceration. This means that incarceration may not be the only reason for low job market performance; the characteristics that caused the conviction could have caused the bad performance in the labor market as well.

The idea that having a job diminishes the chances of recidivism is well established in the criminological literature. See Sampson and Laub (1997) and Harer (1994). A job provides the necessary means for survival, improves self-esteem, increases the attachment to a community and develops the sense of belonging to a group. Therefore, even though finding a job is a difficult task for ex-offenders, a policy that help these people to find a job will likely decrease the chances of recidivism.

During the 1970's and 1980's policy makers in the United States have sponsored evaluations of both in-prison job training programs, as well as post-release (community-based) employment interventions. As to the first type of programs, Visher et al. (2005) assert that these evaluations provide at best mixed results concerning the effectiveness of those interventions. Because of these mixed results, the attention has turned to community-based 
employment programs. However, as outlined by Bloom (2006), "there appear to have been few rigorous studies of employment-focused re-entry models". Moreover, Farrington and Welsh (2005) state that very few evaluations in criminology can be classified as rigorous, in that they are not randomized experiments. Furthermore, it appears that in the criminological literature a randomized experiment is considered synonym for a program with randomized treatment.

During the last decades, sociologists, criminologists and, to a lesser extent, economists have been devising programs to ease the difficult transition faced by ex-offenders during the period of time between release and reintegration into society. These programs are basically of two types: post-release programs and in-prison programs. While the former type of program offers assistance after the individual has been released, the latter type of program starts helping the individual while he/she is in prison. As experience has accumulated, a fundamental goal to a complete reintegration turned out to be job placement. A good job would be necessary not only to provide the basic needs for survival in the short run but also as a key element to secure self-esteem, security and sense of integration in the society as whole.

The Life Insurance for Ex-offenders and the Transitional Aid for Exoffenders are two early examples of employment services for ex-offenders. Both programs offered financial assistance as well as job placement services. The two programs reached similar conclusions: while financial assistance appeared to decrease the recidivism rate, job placement had little or no effect on reducing criminal activity, unless for those who succeeded in securing a job for a long time. The lack of follow-up after placement was conjectured by Milkman et al. (1985) as the main obstacle to the complete success of such programs.

The new paradigm of employment services for ex-offenders have resulted in the appearance of programs that had a strong preoccupation with the post-placement of their clients. These programs have designed follow-up strategies to overcome the major criticism of past experience. Among various programs, three deserve recognition for both being successful and having similar structures: the Comprehensive Offender Resource System (COERS) in Boston, the Safer Foundation (SF) in Chicago and Project JOVE in San Diego. Not surprisingly, the US Department of Justice saw this as a opportunity for assessing the efficacy of employment services programs that contained a follow-up component.

During the period of 1980 - 1985, the National Institute of Justice spon- 
sored a controlled experiment to evaluate the impact of reemployment programs for recent released prisoners. This evaluation was performed by the Lazar Institute in McLean, Virginia. The three aforementioned programs, COERS in Boston, JOVE in San Diego and SF in Chicago, were chosen to participate in the Employment Services for Ex-Offenders Program, henceforth ESEO. A total of 2045 prisoners who volunteered to participate in the program were randomly assigned to either a treatment group or a control group. Those in the first group received, besides the normal services (orientation, screening, evaluation, support services, job development seminar, and job search coaching), special services which consisted of an assignment to a follow-up specialist who provided support during the job search and the 180 days following job placement. The control group received only normal services.

Using OLS regressions, Milkman (2001) found that the effect of the ESEO special services program is negligible. However, this evaluation did not account for the conditional feature of the treatment. The timing of the treatment was completely neglected, which is a very important characteristic of the program under evaluation.

The objective of our paper is to re-evaluate the effect of the ESEO program on recidivism using duration models for job search and recidivism (the latter being defined as the time between release and the first arrest), with the conditional treatment incorporated in the latter duration model. These two durations are interval censored, though.

Carvalho and Bierens (2007) have studied the effect of the ESEO program on recidivism using a bivariate mixed proportional Weibull hazard model for job search and recidivism with common heterogeneity, where both durations are assumed to be independent conditional on the covariates and the heterogeneity variable. The latter is assumed to be Gamma distributed, and integrated out to make the two durations dependent conditional on the covariates only. However, the problem with this approach is that then the job search and recidivism durations are positively related: The longer the job search takes, the longer the time between release and rearrest. This is clearly unrealistic.

Therefore, in the current paper we take a completely different approach, by incorporating treatment in the conditional distribution of the recidivism duration given the covariates and the job search duration. This approach is inspired by (but not exactly equal to) the approach of Abbring and Van 
den Berg (2003). ${ }^{1}$ These authors propose a bivariate mixed proportional hazard model, where one duration is the timing of the treatment and the other one is the duration of interest that is affected by the treatment. In the case of the ESEO program the duration that triggers the treatment is the job search, and the duration of interest is recidivism. However, since both durations are interval-censored and all the covariates are discrete we cannot take unobserved heterogeneity into account, because it is shown in Bierens (2007) that then the mixed proportional hazard model is not identified.

The setup of the paper is as follows. In Section 2 we discuss the ESEO program in more detail, and we describe the data set and the variables involved. Section 3 deals with the attrition problem, which is substantial. It appears that attrition is affected by the group assignment: the attrition rate is higher for the control group than for the treatment group. In Section 4 we conduct a preliminary data analysis by nonparametrically estimating and comparing the interval probabilities for both durations without using covariates, in order to check for evidence of dependence of recidivism on job search, and evidence of a treatment effect. We find neither, and therefore we conclude that at least for the control group the job search and recidivism durations are independent conditional on the covariates, and that if there is a treatment effect then it will likely work via covariates. Section 5 deals with model specification and estimation. In Section 5.1 we discus the Abbring and Van den Berg (2003) model and its relation to our model. In Section 5.2 we estimate and test an interval-censored proportional hazard model for the job search, where in first instance the integrated hazard is left unspecified. Only the location (Chicago, San Diego or Boston) seems to matter for the job search duration, and the results indicate that a Weibull baseline hazard is appropriate for job search. Similarly, in Section 5.3 we estimate and test an interval censored proportional hazard model for the recidivism duration of the control group only. It appears that none of the covariates matter and that the baseline hazard is constant, hence the distribution involved is exponential. In Section 5.4 we extend this exponential model for recidivism to a model that incorporates treatment via covariates, depending on the job search duration, and merge it with the job search model, which are then estimated jointly by maximum likelihood. The results are presented in Section 5.5. It appears that a treatment effect is present, but its magnitude and direction depends on the location and on age. In Section 5.6 we compute

\footnotetext{
${ }^{1}$ In particular their Model 1a.
} 
the actual treatment effect, in terms of expected increase or reduction of the recidivism duration in months, on the basis of our estimations results. In Section 5.7 we compare the results with the preliminary data analysis, and explain why we did not find in first instance evidence of dependence of the job search and recidivism durations and the presence of a treatment effect. In Section 6 we summarize our results and make recommendations for future setup and evaluations of employment programs for ex-offenders. Section 7 is an appendix containing the details of the model selection procedures.

The econometric analysis in this paper has been conducted using the free econometric software package EasyReg International developed by the first author. See Bierens (2006).

\section{The ESEO program and data set}

\subsection{The ESEO Program}

In the ESEO program, after being assigned randomly to either the control or treatment group, the clients enter the intake unit, where they receive initial orientation, screening and evaluation by an intake counsellor. While still in this first phase, to secure survival up to the job search phase, the intake counsellor offers assistance services such as food, transportation, and clothing. After intake, the clients enter the second phase that will prepare them to develop job search skills. In particular, a brief job development seminar is offered which deals with issues like appropriate dress and deportment, typical job rules, goal setting, interviewing techniques, and job hunting strategy. It is assumed that the time spent in the first and second phases are negligible compared to the job search phase. The next and final phase before possible treatment is the job search assistance. This is the traditional job search assistance type of service, as described by Bloom (2006) and Heckman et al. (1999). The job search assistance in the ESEO program is offered equally to both control and treatment groups.

The actual treatment starts upon the first job placement. The people in the control group do not receive help after placement, whereas the people in the treatment group receive follow-up help. The follow-up special services consist mainly of crisis intervention, counselling and, whenever necessary, reemployment assistance, during a period of six month after the first placement. See Timrots (1985), Milkman et al. (1985) and Milkman (2001) for the details 
of the programs and treatment. Thus, even though the split of the sample in treatment group and control group is random, the actual treatment is the follow-up special services after finding a job and is therefore not randomized.

\subsection{The ESEO data}

The ESEO data set consist of 2045 individuals who participated in one of the three programs: 511 in Boston, 934 in Chicago and 600 in San Diego. However, the ICPSR ${ }^{2}$ only made available 1074 usable observations $^{3}$ : 325 in Boston, 489 in Chicago and 260 in San Diego. A large amount of information, sometimes very detailed, was collected from all three sites.

A first important empirical issue is related to the characterization of the population being sampled. Unless very special assumptions are made, the validity of our findings can not be extrapolated beyond the population under sampling. In order to be eligible to participate in the ESEO program an individual must have the following background:

1. Participants voluntarily accepted program services;

2. Participants had been incarcerated at an adult Federal, State, or local correctional facility for at least 3 months and had been released within 6 months of program participation;

3. Participants exhibited a pattern of income-producing offenses.

From the eligibility criteria it is clear that our population is a special, indeed a very special, subset of the population of ex-offenders. Also, since participation is voluntary and there is no information on non-participants (those who did not choose to participate even though they fulfilled requirements 2 and 3), it is not possible to assess the potential bias induced by this selection scheme.

\footnotetext{
${ }^{2}$ The data set used in our present analysis comes from the Inter-University Consortium for Political and Social Research, henceforth ICPSR, University of Michigan, under the study number 8619 .

${ }^{3}$ In the official codebook that ICPSR made available it is written on page 11 that there are 2045 observations. But, on page 20 (FILE STRUCTURE) of the same document it is stated that there are 1215 observations, as was also noticed by Milkman et al. (1985) and Timrots (1985). Thus, the data set contains only 1215 observations. After removing some missing values, we end up with 1074 observations.
} 
Given the initial sample, the individuals were randomly assigned to either the treatment or control group. Control group received the standard services and the treatments group received, in addition to that, emotional support and advocacy during the follow-up period of 180 days after placement. Two durations are of great importance, time spent searching a job and recidivism time. These two variables are interval-censored, however; they are only observed in the form of intervals. Moreover, there is a substantial number of individuals in the sample who do not show up for the common part of the program, i.e., the assistance with the job search. Thus, the endogenous variables are:

- $A$ : Indicator for attrition. $A=1$ means the individual is either a "no show" or a "drop-out", $A=0$ otherwise;

- $T_{s}(s=$ search $)$ is the duration of the job search, i.e., the time between the date of release and the date of placement in the first job after release;

- $T_{c}(c=$ crime $)$ is the recidivism time, i.e., the time between the date of release and the date of the first arrest after release.

As to attrition, one could argue that "no show" and "drop-out" deserve separate treatment, as pointed out by Bloom (1984) and Heckman et al. (1998). However, our data set does not allow for this disaggregation. Besides, most drop-outs occur very early in the program.

The job search duration does not need any explanation, but the meaning of "recidivism" is not unambiguous. There are two ways to measure recidivism outcomes in the ESEO program, via count data or duration data. Detailed data on the number of arrests from date of released to the end of the program for all clients was gathered in the respective state police departments. That was the type of data used in the original evaluation made by Milkman et al. (1985), as well as in almost all literature regarding the evaluation of employment programs for ex-offenders. See Visher et al. (2005) and Seiter and Kadela (2003).

In the criminology literature three possible definitions of recidivism are considered: rearrest, reconviction and re-incarceration. It seems that rearrest has been proven to be the most reliable among the three possible measures, as reported in Beck and Shipley (1989) and Maltz (1984). The latter is what we will use as the duration of recidivism. Thus, in the sequel "(duration 
of) recidivism" should be interpreted as the time between release and first rearrest.

Although, from a methodological point view, the measure of recidivism by means of a duration complicates the model, we believe that this is the right way to proceed because: (a) it conforms to the notion that recidivism is a time interval of occurrence of a first event; (b) unless very special parametric assumptions are made, the number of occurrences in a time interval can not be uniquely determined by a process describing the time of occurrence of the first event, and vice-versa; (c) given the dynamic nature of the treatment, measuring the outcome of the program, i.e., recidivism time, as a duration variable has a much more natural appeal.

The point of departure for the choice of the covariates of the recidivism duration model is Schmidt and Witte (1988): age at release, time served for the sample sentence, sex, education, marital status, race, drug use, supervision status, and dummies that characterize the type of recidivism. However, we have also paid close attention to the criminological literature in recidivism, for instance Gendreau et al. (1996).

The literature on unemployment (and job search) duration has been refined since the 70's. Nowadays, it has a status of a complete theory of unemployment, as it appears in Pissarides (2000). Its empirical contents has been developed since the late 70's and this first wave of empiricism is characterized for being concerned with "reduced" type models. A good account of this first phase can be found in Devine and Kiefer (1991). A final wave is characterized by advocating a "structural" approach to estimation and inference in such models. An updated account of that appears in Van den Berg (1999, 2000). There has been also studies close to ours that try to measure the effect of programs in a context of a model of unemployment and job search duration. See for instance, Abbring and Van den Berg (2003), Abbring et al. (2005), Eberwein et al. (1997) and Van den Berg et al. (2004). In view of those studies, the following set of covariates has been singled out, next to the group assignment indicator:

- $G=1$ if selected in the treatment group, $=0$ if selected in the control group

- DRUGS: Indicator for drugs use during the last 5 years;

- WHITE: Race indicator; 
- MALE: Gender indicator;

- $E D U C_{-} L=1$ if years of schooling $\leq 8,=0$ otherwise;

- $E D U C_{-} H=1$ if years of schooling $>12,=0$ otherwise;

- $A G E$ : Age in years;

- AGE1ARR: Age of first arrest, in years;

- SANDIEGO: Indicator for San Diego;

- $C H I C A G O$ : Indicator for Chicago;

In the econometric model to be developed the job search and recidivism durations $T_{s}$ and $T_{c}$, respectively, are in first instance modeled as continuous latent variables, where treatment kicks in for people in the treatment group if $T_{c}>T_{s}$. The treatment is effective in reducing recidivism if, given the same job search duration $T_{s}$ and the covariates, the recidivism duration $T_{c}$ for the treatment group is larger than for the control group. Note that, since $T_{c}<T_{s}$ is also possible, some people in the treatment group may end up not receiving the treatment at all.

Finding a job may postpone recidivism, but will likely not eliminate it. As Freeman (2003) asserts, "Getting and ex-offender a job does not mean that they will eschew a criminal opportunity if it arises". Thus, in our model the probability that $T_{c}=\infty$ is assumed to be zero. The use of continuous latent variables advocated by us also appears to conform better with what is noted by Fagan and Freeman (1999) and Freeman (2003), namely that the boundary between crime and work is thin and very diffuse for many young men just after release. The two clocks, i.e., time to recidivism and time to get a job, are about to be pushed down every day for these young men.

Although the latent variables $T_{s}$ and $T_{c}$ will be modeled as a joint continuous distribution, conditional on covariates, we only observe them in the form of intervals: $T_{s} \in(a, b], T_{c} \in(p, q], b \leq p$, where $(a, b],(p, q] \in$ $\{(0,1],(1,6],(6,12],(12, \infty)\}$. The unit of measurement for these durations is months. These events are only observed if $A=0$. Given the joint conditional distribution of $T_{s}$ and $T_{c}$, the probabilities of these discrete events can be computed. The latter are then used to form a likelihood function.

As said before, the ex-convicts in the sample have been randomly assigned to either a control group $(G=0)$ or a treatment group $(G=1)$. Both groups 
get standard assistance with the job search. Treatment consists of extra help after finding a job, and is therefore conditional on the job search duration $T_{s}$. The purpose of this study is to determine whether this treatment has an effect on the risk of recidivism, given the covariates listed above.

\section{Attrition}

With a few exceptions, attrition occurs straight away after release. It is therefore reasonable to assume that, conditional on the covariates (stacked in a vector $X), A$ is independent of $T_{s}$ and $T_{c}$, because in most cases the attrition decision $A=1$ is made before $T_{s}$ or $T_{c}$ are realized.

The conditional attrition probability $P[A=1 \mid X]$ has been modeled as a Logit model. It is conceivable that attrition is also affected by the group assignment: The prospect of receiving treatment $(G=1)$ may lead to a lower attrition probability. Therefore, next to the original covariates we have included the group assignment $G$ and the products of $G$ with each of the covariates in the Logit model for $A$. The initial Logit model has been subjected to a sequence of Wald and likelihood ratio tests to clean the model of insignificant covariates. The details of this cleaning process can be found in the Appendix; only the final results are presented, in Table 1.

Table 1. Logit results for attrition

\begin{tabular}{|l|r|r|}
\hline Covariates & Estimates & t-val. \\
\hline$M A L E \times(1-G)$ & 0.7835337 & 3.93 \\
\hline$C H I C A G O \times(1-G)$ & 1.7985664 & 7.94 \\
\hline$C H I C A G O \times G$ & 0.5250147 & 2.71 \\
\hline$S A N D I E G O \times(1-G)$ & 1.0452205 & 3.55 \\
\hline$S A N D I E G O \times G$ & 0.4278509 & 2.05 \\
\hline 1 & -0.7661767 & -5.26 \\
\hline Log-likelihood: & -654.831 & \\
\hline Sample size: & 1074 & \\
\hline
\end{tabular}

It follows from Table 1 that males have a higher attrition rate than females, but only if selected in the control group. Moreover, the attrition rates in Chicago are significantly higher for the control group than for the treatment group, and the same applies to San Diego.

To compare the attrition rates in San Diego and Chicago with the attrition rate in Boston, we have to compare the coefficients of the location 
dummies with the intercept, which leads to the conclusion that the attrition rates in Chicago and San Diego are much higher than in Boston, in particular for the control group, and within the control group the attrition rate in Chicago is higher than in San Diego, although for the treatment group the attrition rates in Chicago and San Diego are not significantly different (the p-value of the Wald test involved is 0.62037 ). The reason may be that the standard service in assisting the ex-inmates with the job search is much more effective in Boston than in San Diego and Chicago, and that therefore the motivation for participation in the program is higher in Boston than in the other two cities. This explanation appears to be corroborated by the results below for the job search duration.

Finally, note that the dependence of attrition on the group assignment does not conflict with our assumption that conditional on the covariates $T_{s}$ and $T_{c}$ are independent of $A$, because $G$ is determined randomly.

\section{Preliminary data analysis}

As said before, the durations $T_{c}$ and $T_{s}$ are only observed in the form of interval indicators, for the intervals $(0,1],(1,6],(6,12]$ and $(12, \infty)$. Table 2 presents the number of observations in each interval and combination of intervals, for both groups as well as separately for the treatment group $(G=$ 1) and the control group $(G=0)$.

By dividing the entries in rows 1-4 in Table 2 by the corresponding row totals we get nonparametric estimates of the conditional probabilities $P\left[T_{c} \in(p, q] \mid T_{s} \in(a, b]\right]$, and in the last rows the unconditional probabilities $P\left[T_{c} \in(p, q]\right]$. These probabilities, times $100 \%$, are presented in Table 3 .

Comparing the entries in rows 1-4 of Table 3 with the corresponding entries in row 5 , it appears that for both groups separately and together all but one of the estimates of $P\left[T_{c} \in(p, q] \mid T_{s} \in(a, b]\right]$ are close to the estimates of $P\left[T_{c} \in(p, q]\right]$. The exception is the estimate of $P\left[T_{c}>12 \mid T_{s} \in(6,12]\right]$ for the control group, but this estimate is based on only two observations.

For our analysis only the probabilities $P\left[T_{c} \in(p, q] \mid T_{s} \in(a, b]\right]$ for $p \geq b$ are relevant. In the Appendix we present the results of tests of the null hypothesis that $P\left[T_{c} \in(p, q] \mid T_{s} \in(a, b]\right]=P\left[T_{c} \in(p, q]\right]$ for $p \geq b$. In all cases the null hypothesis is not rejected at any conventional significance level! Therefore, it seems that the events $T_{c} \in(p, q]$ and $T_{s} \in(a, b]$ for $b \leq p$ are independent. However, if there is a treatment effect one would expect that 
Table 2. Observations per interval $(\mathrm{A}=0)$

\begin{tabular}{|l|r|r|r|r|r|}
\hline$T_{s} \backslash T_{c}$ & $(0,1]$ & $(1,6]$ & $(6,12]$ & $(12, \infty)$ & Total \\
\hline$(0,1]$ & 12 & 56 & 43 & 152 & 263 \\
\hline$(1,6]$ & 6 & 44 & 39 & 112 & 201 \\
\hline$(6,12]$ & 1 & 7 & 6 & 20 & 34 \\
\hline$(12, \infty)$ & 0 & 1 & 1 & 3 & 5 \\
\hline Total & 19 & 108 & 89 & 287 & 503 \\
\hline
\end{tabular}

Treatment group only:

\begin{tabular}{|l|r|r|r|r|r|}
\hline$T_{s} \backslash T_{c}$ & $(0,1]$ & $(1,6]$ & $(6,12]$ & $(12, \infty)$ & Total \\
\hline$(0,1]$ & 9 & 39 & 32 & 105 & 185 \\
\hline$(1,6]$ & 5 & 35 & 30 & 81 & 151 \\
\hline$(6,12]$ & 1 & 4 & 5 & 18 & 28 \\
\hline$(12, \infty)$ & 0 & 1 & 1 & 3 & 5 \\
\hline Total & 15 & 79 & 68 & 207 & 369 \\
\hline
\end{tabular}

Control group only:

\begin{tabular}{|l|r|r|r|r|r|}
\hline$T_{s} \backslash T_{c}$ & $(0,1]$ & $(1,6]$ & $(6,12]$ & $(12, \infty)$ & Total \\
\hline$(0,1]$ & 3 & 17 & 11 & 47 & 78 \\
\hline$(1,6]$ & 1 & 9 & 9 & 31 & 50 \\
\hline$(6,12]$ & 0 & 3 & 1 & 2 & 6 \\
\hline$(12, \infty)$ & 0 & 0 & 0 & 0 & 0 \\
\hline Total & 4 & 29 & 21 & 80 & 134 \\
\hline
\end{tabular}


Table 3. Estimated conditional probabilities

$P\left[T_{c} \in(p, q] \mid T_{s} \in(a, b]\right] \times 100 \%$

\begin{tabular}{|l|r|r|r|r|}
\hline$T_{s} \backslash T_{c}$ & $(0,1]$ & $(1,6]$ & $(6,12]$ & $(12, \infty)$ \\
\hline$(0,1]$ & 5 & 21 & 16 & 58 \\
\hline$(1,6]$ & 3 & 22 & 19 & 56 \\
\hline$(6,12]$ & 3 & 20 & 18 & 59 \\
\hline$(12, \infty)$ & 0 & 20 & 20 & 60 \\
\hline$(0, \infty)$ & 4 & 21 & 18 & 57 \\
\hline
\end{tabular}

Treatment group only:

\begin{tabular}{|l|r|r|r|r|}
\hline$T_{s} \backslash T_{c}$ & $(0,1]$ & $(1,6]$ & $(6,12]$ & $(12, \infty)$ \\
\hline$(0,1]$ & 5 & 21 & 17 & 57 \\
\hline$(1,6]$ & 3 & 23 & 20 & 54 \\
\hline$(6,12]$ & 4 & 14 & 18 & 64 \\
\hline$(12, \infty)$ & 0 & 20 & 20 & 60 \\
\hline$(0, \infty)$ & 4 & 21.5 & 18.5 & 56 \\
\hline
\end{tabular}

Control group only (? = undefined):

\begin{tabular}{|l|r|r|r|r|}
\hline$T_{s} \backslash T_{c}$ & $(0,1]$ & $(1,6]$ & $(6,12]$ & $(12, \infty)$ \\
\hline$(0,1]$ & 4 & 22 & 14 & 60 \\
\hline$(1,6]$ & 2 & 18 & 18 & 62 \\
\hline$(6,12]$ & 0 & 50 & 17 & 33 \\
\hline$(12, \infty)$ & $?$ & $?$ & $?$ & $?$ \\
\hline$(0, \infty)$ & 3 & 21.6 & 15.7 & 59.7 \\
\hline
\end{tabular}


in the case $G=1$ these events are dependent.

These results are compatible with independence of $T_{c}$ and $T_{s}$ conditional on the covariates, provided that the vector $X$ of covariates can be partitioned as

$$
X=\left(X_{s}^{\prime}, X_{c}^{\prime}\right)^{\prime} \text {, where } X_{s} \text { and } X_{c} \text { are independent, }
$$

and

$$
P\left[T_{s} \leq t \mid X\right]=P\left[T_{s} \leq t \mid X_{s}\right], P\left[T_{c} \leq t \mid X\right]=P\left[T_{c} \leq t \mid X_{c}\right] .
$$

Therefore, at least for the control group, we will assume that the conditions (1) and (2) hold.

If there is a treatment effect, then for $t>T_{s}$,

$$
P\left[T_{c} \leq t \mid T_{s}, X_{c}\right] \neq P\left[T_{c} \leq t \mid X_{c}\right],
$$

so that for the treatment group,

$$
\begin{aligned}
& P\left[T_{c} \in(p, q], T_{s} \in(a, b]\right]=P\left[T_{c} \in(p, q]\right] P\left[T_{s} \in(a, b]\right] \\
& +\int_{a}^{b}\left(P\left[T_{c} \in(p, q] \mid T_{s}=t_{s}\right]-P\left[T_{c} \in(p, q]\right]\right) d P\left[T_{s} \leq t_{s}\right] .
\end{aligned}
$$

If the latter term is small then the events $T_{c} \in(p, q]$ and $T_{s} \in(a, b]$ are approximately independent. Thus, if the dependence of $P\left[T_{c} \leq t \mid T_{s}, X_{c}\right]$ on $T_{s}$ is substantially reduced after $X_{c}$ is integrated out, then the inequality (3) may no longer be detectable. Therefore, a treatment effect may still be possible, but if so it will likely work via the covariates $X$.

\section{$5 \quad$ Modeling strategy and empirical results}

\subsection{The Abbring-Van den Berg model}

Abbring and Van den Berg (2003) consider the problem of identification of treatment effects in a bivariate mixed proportional hazard model, where one duration, $S$, is the timing of an intervention on another duration $Y$. In their Model 1a they specify the hazard functions of these duration as

$$
\theta_{S}(t \mid X, V)=\lambda_{S}(t) \varphi_{S}(X) V_{S}
$$


for the duration $S$ and

$$
\theta_{S}(t \mid S, X, V)= \begin{cases}\lambda_{Y}(t) \varphi_{Y}(X) V_{Y} & \text { if } t \leq S \\ \lambda_{Y}(t) \varphi_{Y}(X) \delta(t \mid S, X) V_{Y} & \text { if } t>S\end{cases}
$$

for the duration $Y$, where $X$ is a vector of covariates with support $\mathbb{X}, V=$ $\left(V_{S}, V_{Y}\right)^{\prime} \in(0, \infty) \times(0, \infty)$ is a vector of dependent unobserved heterogeneity variables that are independent of $X$, the $\lambda_{i}(t)$ and $\varphi_{i}(X), i=S, Y$, are the baseline and systematic hazards, respectively, and $\delta(t \mid S, X)$ represents the conditional treatment effect. Implicit in this specification is the "no anticipation" condition ${ }^{4}$

$$
\theta_{S}\left(t \mid s_{1}, X, V\right)=\theta_{S}\left(t \mid s_{2}, X, V\right) \text { if } t \leq \min \left(s_{1}, s_{2}\right)
$$

The focus in Abbring and Van den Berg (2003) is on nonparametric identification of the baseline and systematic hazards $\lambda_{i}(t)$ and $\varphi_{i}(X), i=S, Y$, the treatment function $\delta($.$) and the joint distribution G(v)$ of $V$, rather than on estimation. In particular, they show that this model is non-parametrically identified if

$$
\left\{\left(\varphi_{S}(x), \varphi_{Y}(x)\right)^{\prime} ; x \in \mathbb{X}\right\} \text { contains an open set in } \mathbb{R}^{2},
$$

and $E\left[V_{S}\right]<\infty, E\left[V_{Y}\right]<\infty$.

In the case of the ESEO program, $S$ is the job search duration $T_{s}$ and $Y$ is the recidivism duration $T_{c}$. Since $T_{s}$ and $T_{c}$ are interval censored, and the support $\mathbb{X}$ of the covariates is countable, which violates condition (6), we cannot take unobserved heterogeneity into account. See Bierens (2007, Section 9). Besides, the effective sample size is too small for semi-nonparametric estimation of $G(v)$. See Bierens and Carvalho (2007, Section 3.4). Thus, we have to set $V_{S}=V_{Y}=1$ in (4) and (5).

We specify the proportional hazard of job search $T_{s}$ similar to (4), with $V_{S}=1$, and we specify the conditional hazard of the recidivism duration $T_{c}$ for the control group $(G=0)$ as well as for the treatment group $(G=1)$ in the case $t \leq T_{s}$ similar to (5) for the case $V_{Y}=1, t<S$. Moreover, we specify the systematic hazards parametrically in the usual way, as the $\exp ($. of linear combinations of the covariates. Thus, in our notation,

$$
\theta_{s}(t \mid X)=\exp \left(\beta_{s}^{\prime} X_{s}\right) \lambda_{s}(t)
$$

\footnotetext{
${ }^{4}$ Abring and Van den Berg (2003, Assumption 1).
} 
is the conditional hazard of the job search duration $T_{s}$, with $X_{s}$ a subvector of covariates relevant for job search, and

$$
\theta_{c}\left(t \mid T_{s}, X, G\right)= \begin{cases}\exp \left(\beta_{c}^{\prime} X_{c}\right) \lambda_{c}(t) & \text { if } t \leq T_{s} \\ \exp \left(\beta_{c}^{\prime} X_{c}\right) \delta\left(t \mid T_{s}, X, G\right) \lambda_{c}(t) & \text { if } t>T_{s}\end{cases}
$$

is the conditional hazard of the recidivism duration $T_{c}$, with $X_{c}$ a subvector of covariates relevant for recidivism, where $\delta\left(t \mid T_{s}, X, G\right)=1$ for the control group $G=0$, and $\delta\left(t \mid T_{s}, X, G\right)$ is to be determined for the treatment group $G=1$. This specification is in accordance with our finding in the previous section that for the control group the durations $T_{s}$ and $T_{c}$ seem to be independent.

Given the proportional hazard structure of the model, the subvectors $X_{s}$ and $X_{c}$ of the covariates and the baseline hazards $\lambda_{s}(t)$ and $\lambda_{c}(t)$ will be specified in a data-driven way. Since the duration $T_{s}$ and $T_{c}$ are intervalcensored, there is in first instance no need to specify the baseline hazards parametrically. This enables us to let the data determine how the baseline hazards look like, and what the relevant subvectors $X_{s}$ and $X_{c}$ are. Only the treatment effect factor $\delta\left(t \mid T_{s}, X, G\right)$ has to be specified parametrically.

\subsection{Job search}

Given the hazard (7) the conditional survival function of $T_{s}$ is

$$
S_{s}(t \mid X)=\exp \left(-\exp \left(\beta_{s}^{\prime} X_{s}\right) \Lambda_{s}(t)\right)
$$

where $\Lambda_{s}(t)=\int_{0}^{t} \lambda_{s}(\tau) d \tau$ is the integrated hazard. In first instance we have selected for $X_{s}$ all available covariates: $X_{s}=X$. Then

$$
\begin{aligned}
& P\left[T_{s} \in(a, b] \mid X\right]=S_{s}(a \mid X)-S_{s}(b \mid X) \\
& =\exp \left(-\exp \left(\beta_{s}^{\prime} X\right) \Lambda_{s}(a)\right)-\exp \left(-\exp \left(\beta_{s}^{\prime} X\right) \Lambda_{s}(b)\right) .
\end{aligned}
$$

Since we can only estimate $\Lambda_{s}(t)$ for $t \in\{1,6,12\}$, we may without loss of generality assume that $\Lambda_{s}(t)$ is piecewise linear:

$$
\begin{aligned}
\Lambda_{s}\left(t \mid \alpha_{s}\right) & =\sum_{k=1}^{i-1} \alpha_{k}\left(b_{k}-b_{k-1}\right)+\alpha_{i}\left(t-b_{i-1}\right) \text { for } t \in\left(b_{i-1}, b_{i}\right], \\
b_{0} & =0, b_{1}=1, b_{2}=6, b_{3}=12 \\
\alpha_{i} & >0 \text { for } i=1, \ldots, 3, \alpha_{s}=\left(\alpha_{1}, \alpha_{2}, \alpha_{3}\right)^{\prime}
\end{aligned}
$$


Note that $\Lambda_{s}\left(t \mid \alpha_{s}\right)$ is homogenous of degree one in $\alpha_{s}: \Lambda_{s}\left(t \mid c . \alpha_{s}\right)=c . \Lambda_{s}\left(t \mid \alpha_{s}\right)$. Therefore, we cannot allow a constant 1 in $X$.

In first instance we have included all available covariates in the job search model. Then we conduct a series of Wald and likelihood ratio tests to determine the subvector $X_{s}$ of covariates that are relevant for the job search duration. Moreover, on the basis of the estimation results for the piecewise linear integrated baseline hazard (9) we deduct the functional form of the underlying smooth baseline hazard $\lambda_{s}(t)$. The details of this specification analysis can be found in the Appendix.

We find that only the location dummy variables matter for job search, so that

$$
X_{s}=(C H I C A G O, S A N D I E G O)^{\prime} .
$$

Moreover, we cannot reject the null hypothesis that the baseline hazard is of the Weibull type. Thus, the survival function now takes the form

$$
\begin{aligned}
S_{s}(t \mid X) & =\exp \left(-\exp \left(\beta_{s}^{\prime} X_{s}\right) \alpha_{1, s} t^{\alpha_{2, s}}\right) \\
& =\exp \left(-\exp \left(\beta_{s}^{\prime} X_{s}+\ln \left(\alpha_{1, s}\right)\right) t^{\alpha_{2, s}}\right) .
\end{aligned}
$$

The estimation results for this model are presented in Table 4.

Table 4. Job search

\begin{tabular}{|l|r|r|}
\hline Covariates & Estimates & t-val. \\
\hline CHICAGO & -1.228695 & -7.988 \\
\hline SANDIEGO & -0.379488 & -2.745 \\
\hline Parameters & & \\
\hline$\alpha_{1, s}$ & 1.197083 & 10.880 \\
\hline$\alpha_{2, s}$ & 0.884122 & 15.957 \\
\hline Log-likelihood: & -422.063 & \\
\hline Sample size: & 503 & \\
\hline
\end{tabular}

The results in Table 4 are only final with respect to the model specification. The coefficients involved will be re-estimated jointly with those of the recidivism model specified below. At that point we will interpret the results.

\subsection{Recidivism of the control group}

In view of the results of the preliminary data analysis, we will assume that conditional on the covariates the recidivism duration $T_{c}$ for the control group 
is independent of the job search duration $T_{s}$. Moreover, similar to the job search case, the conditional survival function of $T_{c}$ for the control group will be modeled as a proportional hazard model:

$$
S_{c}(t \mid X)=\exp \left(-\exp \left(\beta_{c}^{\prime} X\right) \Lambda_{c}(t)\right)
$$

where $\Lambda_{c}(t)$ is the integrated hazard. Again, we may without loss of generality assume that $\Lambda_{c}(t)$ is piecewise linear, as in (9).

We have followed the same specification strategy as for job search. The details can be found in the Appendix. Surprisingly, we find that none of the covariates matter for recidivism, and that the baseline hazard is constant. Thus, the distribution of $T_{c}$ for the control group is exponential, so that the survival function involved takes the form

$$
S_{c}(t \mid X)=\exp \left(-\alpha_{c} \cdot t\right)
$$

The maximum likelihood estimation result for $\alpha_{c}$ is presented in Table 5:

Table 5. Recidivism $(G=0)$

\begin{tabular}{|l|r|r|}
\hline Parameter & Estimate & t-val. \\
\hline$\alpha_{c}$ & 0.043681 & 7.396 \\
\hline Log-likelihood: & -139.357 & \\
\hline Sample size: & 134 & \\
\hline
\end{tabular}

Note that this result implies that $E\left[T_{c} \mid G=0\right]=1 / \alpha_{c} \approx 23$ months, and that approximately,

$$
\begin{aligned}
& P\left(T_{c} \in(0,1] \mid G=0\right) \quad \approx 0.04274 \\
& P\left(T_{c} \in(1,6] \mid G=0\right) \quad \approx 0.18781 \\
& P\left(T_{c} \in(6,12] \mid G=0\right) \approx 0.17740 \\
& P\left(T_{c}>12 \mid G=0\right) \quad \approx 0.59205
\end{aligned}
$$

\subsection{Incorporating conditional treatment}

For the treatment group $(G=1)$, treatment is only received if $T_{c}>T_{s}$. Therefore we will assume that if $T_{c} \leq T_{s}$ the distribution of $T_{c}$ is the same as for the control group:

$$
P\left[T_{c} \leq t \mid T_{s}, X, G=1\right]=1-\exp \left(-\alpha_{c} . t\right) \text { if } t \leq T_{s}
$$


See (11). This is the "no anticipation" condition in Abbring and Van den Berg (2003, Assumption 1). Admittedly, in view of the effect of group assignment on attrition this may be a strong assumption. However, it follows from Table 2 that the number of individuals in the treatment group for which $T_{c} \leq T_{s}$ is relatively small, hence if this assumption is incorrect its impact on the results will be minor.

Recall from the results of the preliminary data analysis that if there is a treatment effect then it will likely work via the covariates. Therefore, let

$$
\begin{aligned}
& P\left[T_{c} \leq t \mid T_{s}, X_{c}, G=1\right]=1-\exp \left(-\alpha_{c} \cdot T_{s}\right) \\
& \times \exp \left(-\alpha_{c} \cdot \exp \left(\beta_{c}^{\prime} X_{c}\right) \cdot\left(t-T_{s}\right)\right) \text { if } t>T_{s},
\end{aligned}
$$

where $X_{c}$ is the vector of covariates involved, which now also includes 1 for the constant term. Thus, the conditional survival function of $T_{c}$ given $T_{s}, X_{c}$, and $G$ is specified as

$$
\begin{aligned}
& S_{c}\left(t \mid T_{s}, X_{c}, G\right)=P\left[T_{c}>t \mid T_{s}, X_{c}, G\right]=I\left(t \leq T_{s}\right) \exp \left(-\alpha_{c} \cdot t\right) \\
& +I\left(t>T_{s}\right) \exp \left(-\alpha_{c} \cdot T_{s}\right) \cdot \exp \left(-\alpha_{c} \cdot \exp \left(G \cdot \beta_{c}^{\prime} X_{c}\right) \cdot\left(t-T_{s}\right)\right),
\end{aligned}
$$

where $I($.$) is the indicator function. { }^{5}$

Note that the corresponding conditional hazard takes the form (8):

$$
\begin{aligned}
\theta_{c}\left(t \mid T_{s}, X, G\right) & =\frac{-\partial S_{c}\left(t \mid T_{s}, X_{c}, G\right) / \partial t}{S_{c}\left(t \mid T_{s}, X_{c}, G\right)} \\
& =\alpha_{c}\left(1+I\left(t>T_{s}\right)\left(\exp \left(G \cdot \beta_{c}^{\prime} X_{c}\right)-1\right)\right),
\end{aligned}
$$

where the systematic hazard $\exp \left(\beta_{c}^{\prime} X_{c}\right)$ is now equal to 1 , the baseline hazard $\lambda_{c}(t)$ is equal to the constant $\alpha_{c}$, and

$$
\delta\left(t \mid T_{s}, X, G\right)=1+I\left(t>T_{s}\right)\left(\exp \left(G \cdot \beta_{c}^{\prime} X_{c}\right)-1\right) .
$$

Next, rewrite the survival function of $T_{s}$ as

$$
S_{s}(t \mid X)=\exp \left(-\exp \left(\beta_{s}^{\prime} X_{s}\right) t^{\alpha_{s}}\right),
$$

where now $X_{s}=(C H I C A G O, S A N D I E G O, 1)^{\prime}$ and $\alpha_{s}=\alpha_{2, s}$. See Table

\footnotetext{
${ }^{5} I($ true $)=1, I($ false $)=0$.
} 
4. Then it follows from (12) and (13) that for $0 \leq a<b \leq p<q$,

$$
\begin{aligned}
& P\left[T_{c} \in(p, q], T_{s} \in(a, b] \mid X, G\right] \\
& =\int_{a}^{b} S_{c}\left(t \mid t_{s}, X_{c}, G\right) d\left(-S_{s}\left(t_{s} \mid X_{s}\right)\right) \\
& =-\int_{a}^{b} \exp \left(-\alpha_{c} \cdot\left(1-\exp \left(G \cdot \beta_{c}^{\prime} X_{c}\right)\right) t_{s}\right) d\left(\exp \left(-\exp \left(\beta_{s}^{\prime} X_{s}\right) t_{s}^{\alpha_{s}}\right)\right) \\
& \times\left(\exp \left(-\alpha_{c} \cdot \exp \left(G \cdot \beta_{c}^{\prime} X_{c}\right) \cdot p\right)-\exp \left(-\alpha_{c} \cdot \exp \left(G \cdot \beta_{c}^{\prime} X_{c}\right) \cdot q\right)\right) \\
& =\int_{S_{s}\left(b \mid X_{s}\right)}^{S_{s}\left(a \mid X_{s}\right)} \exp \left[-\alpha_{c} \cdot \exp \left(-\alpha_{s}^{-1} \beta_{s}^{\prime} X_{s}\right)\right. \\
& \left.\times\left(1-\exp \left(G \cdot \beta_{c}^{\prime} X_{c}\right)\right)(\ln (1 / u))^{1 / \alpha_{s}}\right] d u \\
& \times\left(\exp \left(-\alpha_{c} \cdot \exp \left(G \cdot \beta_{c}^{\prime} X_{c}\right) \cdot p\right)-\exp \left(-\alpha_{c} \cdot \exp \left(G \cdot \beta_{c}^{\prime} X_{c}\right) \cdot q\right)\right) .
\end{aligned}
$$

The parameters involved can now be (re-)estimated by maximum likelihood. ${ }^{6}$

Note that if there is a treatment effect then the effect is positive, in the sense that treatment reduces the risk of recidivism, if for $t>T_{s}$,

$$
P\left[T_{c}>t \mid T_{s}, X_{c}, G=1\right]>P\left[T_{c}>t \mid T_{s}, X_{c}, G=0\right],
$$

which is the case if $\beta_{c}^{\prime} X_{c}<0$.

\subsection{Joint maximum likelihood results}

In first instance we have chosen for $X_{s}$ in (12) the vector of all available covariates, including 1 for the constant term. Again, we have conducted a series of Wald and likelihood ration test to remove insignificant covariates. See the Appendix for the details. The result (see Table 6) is that only two covariates matter for treatment: Age and the location dummy Boston.

Note that the estimation results for job search are very close to the corresponding estimates in Table 4, as expected. Moreover, observe that the estimate of $\alpha_{c}$ in Table 6 is close to the estimate of $\alpha_{c}$ in Table 5.

The significant negative signs of the location dummies in the left-side panel of Table 6 indicate that the job search takes longer in Chicago and San Diego than in Boston, and in Chicago longer than in San Diego. Thus, its

\footnotetext{
${ }^{6}$ This has been done via the user-defined maximum likelihood module in EasyReg International. See Bierens (2006) for the latter.
} 
Table 6. Job search, recidivism and treatment effects

\begin{tabular}{|l|r|r|}
\hline Job search & & \\
\hline Parameter & Estimate & t-val. \\
\hline$\alpha_{s}$ & 0.875049 & 12.320 \\
\hline Covariates & Estimates & t-val. \\
\hline$C H I C A G O$ & -1.225155 & -7.440 \\
\hline$S A N D I E G O$ & -0.324369 & -2.141 \\
\hline 1 & 0.184070 & 1.868 \\
\hline Recidivism & & \\
\hline Parameter & Estimate & t-val. \\
\hline$\alpha_{c}$ & 0.041905 & 7.664 \\
\hline Covariates & Estimates & t-val. \\
\hline$B O S T O N$ & 0.425046 & 2.304 \\
\hline$A G E$ & -0.045503 & -2.720 \\
\hline 1 & 1.222241 & 2.536 \\
\hline Log-Likelihood: & -847.358 & \\
\hline Sample size: & 503 & \\
\hline
\end{tabular}

seems that the ex-convicts in Boston receive more or better help with the job search than in the other two cities. Other possible reasons for these effects are differences in labor market conditions, efficiency of programs, attitudes of employers regarding ex-convicts, and policies regarding the release of criminal records information, to mention a few. However, we do not have enough data information to pinpoint the reasons for the differences in job search durations in these three locations.

Recall that for the control group the recidivism duration has an exponential distribution which does not depend on covariates. The two covariates in the right-hand side panel of Table 6 are therefore related to the effect of treatment for the treatment group only. How to interpret these results will be discussed in the next subsection. 


\subsection{Treatment effects}

It is straightforward to verify from (12) that

$$
\begin{aligned}
& P\left[T_{c} \leq t \mid T_{c}>T_{s}, T_{s}, X_{c}, G\right] \\
& =1-\exp \left(-\alpha_{c} \cdot \exp \left(G \cdot \beta_{c}^{\prime} X_{c}\right) \cdot\left(t-T_{s}\right)\right) I\left(t>T_{s}\right)
\end{aligned}
$$

hence

$$
E\left[T_{c} \mid T_{c}>T_{s}, T_{s}, X_{c}, G\right]=T_{s}+\alpha_{c}^{-1} \exp \left(-G \cdot \beta_{c}^{\prime} X_{c}\right)
$$

and thus

$$
\begin{aligned}
E\left[T_{c} \mid T_{c}\right. & \left.>T_{s}, T_{s}, X_{c}, G=1\right]-E\left[T_{c} \mid T_{c}>T_{s}, T_{s}, X_{c}, G=0\right] \\
& =\alpha_{c}^{-1}\left(\exp \left(-\beta_{c}^{\prime} X_{c}\right)-1\right) .
\end{aligned}
$$

This expression may be interpreted as (a version of) the conditional treatment effect. Thus, the treatment has a positive effect, in the sense that treatment increases the expected time between release and rearrest, if $\beta_{c}^{\prime} X_{c}<0$, regardless the job search duration.

It follows from the results in Table 6 that

$$
\widehat{\beta}_{c}^{\prime} X_{c}=1.222241+0.425046 . B O S T O N-0.045503 . A G E .
$$

As to the "Boston" effect, (15) is larger for Boston than for the other two locations, so that ceteris paribus the conditional treatment effect on recidivism in Boston is less than in Chicago and San Diego. This difference increases with age. Moreover, it follows from (15) the treatment reduces the risk of recidivism in Chicago and San Diego if

$$
A G E>\frac{1.222241}{0.045503} \approx 27,
$$

and in Boston if

$$
A G E>\frac{2.180753}{0.045503} \approx 36
$$

Note that Uggen (2000), using a different data set and methodology, concluded that work programs reduce recidivism only for ex-convicts over the age of 26, which corresponds to our finding (16). Thus, in general, treatment only reduces the risk of recidivism for older ex-inmates, and increases the risk of recidivism for younger ex-inmates! With how much is illustrated in Figure 1. 


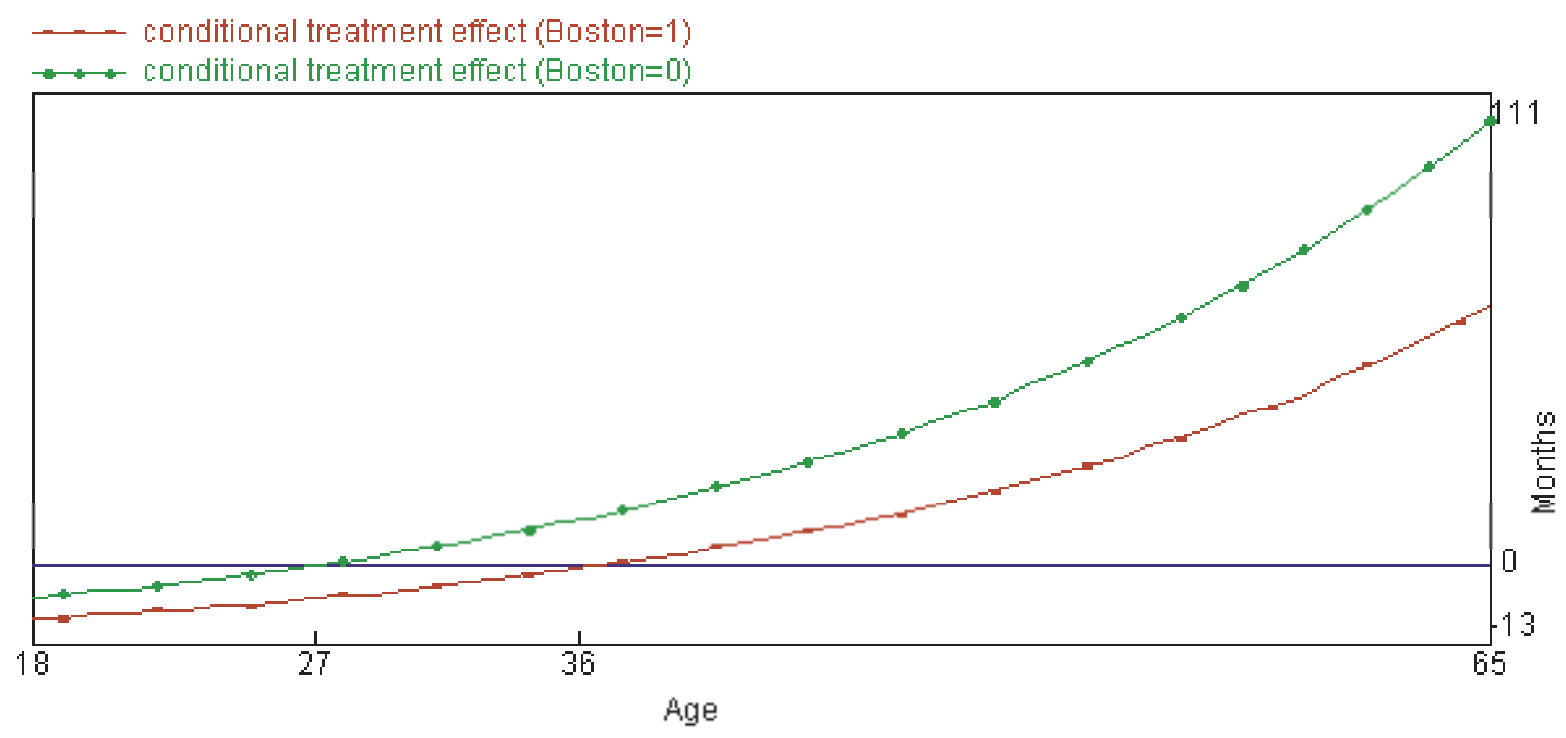

Figure 1: Conditional treatment effect on recidivism

\subsection{Comparison with the preliminary data analysis}

In the preliminary data analysis we have argued that if the dependence of $P\left[T_{c} \leq t \mid T_{s}, X_{c}\right]$ on $T_{s}$ is substantially reduced after $X_{c}$ is integrated out, then the inequality (3) is no longer detectable. To verify this conjecture, we have estimated $P\left[T_{c} \in(p, q] \mid T_{s}=t_{s}, X_{c}, G=1\right]$ for $t_{s}<p$ on the basis of the results in Table 6 and then averaged these estimates over the treatment group, which yield the results in Table 7.

Table 7. Estimated $P\left[T_{c} \in(p, q] \mid T_{s}=t_{s}, G=1\right]$

\begin{tabular}{|l|l|r|l|r|r|}
\hline$p$ & $q$ & Range of $t_{s}$ & Mean & Minimum & Maximum \\
\hline 1 & 6 & $0 \rightarrow 1$ & 0.20697 & 0.20567 & 0.20829 \\
\hline 6 & 12 & $0 \rightarrow 1$ & 0.18507 & 0.18405 & 0.18610 \\
\hline 6 & 12 & $1 \rightarrow 6$ & 0.19164 & 0.18610 & 0.19753 \\
\hline 12 & $\infty$ & $0 \rightarrow 1$ & 0.56324 & 0.56194 & 0.56457 \\
\hline 12 & $\infty$ & $1 \rightarrow 6$ & 0.57202 & 0.56457 & 0.58015 \\
\hline 12 & $\infty$ & $6 \rightarrow 12$ & 0.59190 & 0.58015 & 0.60480 \\
\hline
\end{tabular}

Indeed, the dependence of $P\left[T_{c} \in(p, q] \mid T_{s}=t_{s}, G=1\right]$ on $t_{s}<p$ is weak, which explains why we could not find any dependence. 


\section{Conclusions}

In contrast with previous studies we find that the ESEO program has an effect on recidivism, but this effect depends on age and location: the ESEO program reduces the risk of recidivism only for ex-inmates over the age of 27 in San Diego and Chicago, and over the age of 36 in Boston, but increases the risk of recidivism for the other ex-inmates in the treatment group. However, in view of Figure 1 it seems that the positive effect of the treatment for the older ex-convicts outweighs the negative effect for the younger ex-convicts, in terms of the expected number of months with which the rearrest will be postponed. Hence, heterogeneity of impact is an important point to consider when evaluating reentry programs.

One of the agreements in the literature on program evaluation is that given the specificities of the groups of people who usually make use of those services, some programs that work well for a given group may not work so well for others. In other words, the effects of programs may be heterogenous. See, for example, Heckman et al. (1999). That is exactly what we find.

Our results provide evidence that employment programs for ex-offenders can reduce recidivism, provided that these programs take the heterogeneity of the population of ex-offenders into account. A program that is uniform for all ex-offenders may not yield the expected results. This paper has therefore made a positive contribution to the debate in the criminological literature about the likely effects of ex-offenders employment programs. See Visher et al. (2005).

In unemployment duration studies, age and education are usually important factors for the length of the unemployment spell. In the case under review, however, the job search duration does not depend on any individualspecific covariates. This may be due to the fact that all individuals in the sample have one dominant characteristic in common, namely being exconvicts. Moreover, our finding that the job search duration only depends on the location may also indicate that this duration mainly measures the efforts of the program staff in the three locations in finding jobs for the ex-inmates, rather than the efforts of the ex-inmates themselves.

It is important for the scientific evaluation of future employment programs for ex-offenders that more and better data are made available. For instance, it would have been helpful for our analysis if we have had details about the teams that help each ex-inmate in finding a job, such as their case loads, and more details about the ex-offenders themselves, such their criminal 
and employment history, the status of their release (parole, probation, or unconditional release), time served versus sentence time, family characteristics, level of participation in the job search, the types of jobs searched for, and past and presents employer's evaluations. Moreover, we fail to understand the reason why in the ESEO data the job search and recidivism durations were interval censored. If we had observed uncensored durations, we would have been able to conduct a more sophisticated econometric analysis, for example by including unobserved heterogeneity in our model. Finally, future program evaluations should pay more attention to the attrition problem, in particular by trying to trace down the drop-outs and gathering information about the reasons for dropping out.

\section{Appendix}

\subsection{Attrition}

The initial Logit results for attrition are presented in Table A.1.

The parameters in Table A.1 indicated by an asterix (*) are individually insignificant at the $5 \%$ significance level. The Wald test that they are also jointly zero does not reject the null hypothesis at any conventional significance level. Therefore, we have re-estimated the model without these covariates. The results are presented in Table A.2.

The likelihood-ratio (LR) test that the model in Table A.1 can be reduced to the model in Table A.2 has p-value 0.32867. Therefore, the null hypothesis involved cannot be rejected. The Wald test of the hypothesis that the parameters of $M A L E$ and $M A L E \times G$ add up to zero has p-value 0.55700, hence we may replace these two covariates with $M A L E \times(1-G)$ only, with approximately the same coefficient as $M A L E$ in Table A.2. Thus, males have a higher attrition rate than females, ceteris paribus, but only if selected in the control group. The Wald test of the hypothesis that the coefficients of $C H I C A G O$ and $C H I C A G O \times G$ add up to zero has p-value 0.01127 , hence this hypothesis should be rejected. The same applies to the hypothesis that the coefficients of $S A N D I E G O$ and $S A N D I E G O \times G$ add up to zero: The p-value of the Wald test involved is 0.04173 .

To highlight the effect of group selection on attrition we have re-estimated the attrition model once more. The final results are presented in Table 1. 
Table A.1. Initial Logit results for attrition

\begin{tabular}{|l|r|r|l|}
\hline Covariates & Estimates & t-val. & \\
\hline$A G E$ & 0.0221627 & 1.08 & $*$ \\
\hline$A G E 1 A R R$ & -0.0404668 & -1.36 & $*$ \\
\hline$D R U G S$ & 0.1204060 & 0.48 & $*$ \\
\hline$W H I T E$ & -0.2757420 & -1.08 & $*$ \\
\hline$M A L E$ & 1.0069009 & 2.85 & \\
\hline$C H I C A G O$ & 1.8851845 & 6.92 & \\
\hline$S A N D I E G O$ & 1.2054894 & 3.67 & \\
\hline$E D U C \_L$ & 0.1782564 & 0.48 & $*$ \\
\hline$E D U C \_H$ & -0.3512399 & -0.91 & $*$ \\
\hline$A G E \times G$ & -0.0110983 & -0.45 & $*$ \\
\hline$A G E 1 A R R \times G$ & 0.0730824 & 2.09 & $*$ \\
\hline$D R U G S \times G$ & -0.0553598 & -0.18 & $*$ \\
\hline$W H I T E \times G$ & 0.4943870 & 1.55 & $*$ \\
\hline$M A L E \times G$ & -0.9730099 & -2.16 & \\
\hline$C H I C A G O \times G$ & -1.3287316 & -3.79 & \\
\hline$S A N D I E G O \times G$ & -0.8245169 & -2.07 & \\
\hline$E D U C \_L \times G$ & 0.0991291 & 0.20 & $*$ \\
\hline$E D U C \_H \times G$ & -0.0063107 & -0.01 & $*$ \\
\hline$G$ & -0.7824471 & -0.82 & $*$ \\
\hline 1 & -0.9178355 & -1.17 & \\
\hline Log-likelihood: & -647.325 & & \\
\hline Sample size: & 1074 & & \\
\hline
\end{tabular}

Table A.2. Logit results for attrition: Model 2

\begin{tabular}{|l|r|r|}
\hline Covariates & \multicolumn{1}{|c|}{ Estimates } & \multicolumn{1}{c|}{ t-val. } \\
\hline$M A L E$ & 0.8708543 & 3.51 \\
\hline$M A L E \times G$ & -0.7345117 & -3.41 \\
\hline$C H I C A G O$ & 1.8323490 & 7.84 \\
\hline$C H I C A G O \times G$ & -1.3317171 & -4.58 \\
\hline$S A N D I E G O$ & 1.0773423 & 3.59 \\
\hline SANDIEGO $\times G$ & -0.6531673 & -1.88 \\
\hline 1 & -0.8711105 & -3.78 \\
\hline Log-likelihood: & -654.658 & \\
\hline Sample size: & 1074 & \\
\hline
\end{tabular}




\subsection{Preliminary data analysis}

To test whether

$$
\begin{aligned}
& P\left[T_{c} \in(1,6]\right]=P\left[T_{c} \in(1,6] \mid T_{s} \in(0,1]\right] \\
& P\left[T_{c} \in(6,12]\right]=P\left[T_{c} \in(6,12] \mid T_{s} \in(0,1], T_{s} \in(1,6]\right] \\
& P\left[T_{c} \in(12, \infty)\right] \\
& =P\left[T_{c} \in(12, \infty) \mid T_{s} \in(0,1], T_{s} \in(1,6], T_{s} \in(6,12]\right]
\end{aligned}
$$

we have estimated Logit models for each of these conditional probabilities, and for each group separately:

$$
\begin{aligned}
& P\left[T_{c} \in(1,6] \mid T_{s} \in(0,1]\right]=F\left(\beta_{1,0}+\beta_{1,1} I\left(T_{s} \in(0,1]\right)+\beta_{1,2}\right) \\
& P\left[T_{c} \in(6,12] \mid T_{s} \in(0,1], T_{s} \in(1,6]\right] \\
& =F\left(\beta_{2,0}+\beta_{2,1} I\left(T_{s} \in(0,1]\right)+\beta_{2,2} I\left(T_{s} \in(1,6]\right)\right) \\
& P\left[T_{c} \in(12, \infty) \mid T_{s} \in(0,1], T_{s} \in(1,6], T_{s} \in(6,12]\right] \\
& =F\left(\beta_{3,0}+\beta_{3,1} I\left(T_{s} \in(0,1]\right)+\beta_{3,2} I\left(T_{s} \in(1,6]\right)+\beta_{3,3} I\left(T_{s} \in(6,12]\right)\right)
\end{aligned}
$$

where $F(x)$ is the logistic distribution function. However, in the case $G=0$ we have $I\left(T_{s} \in(0,1]\right)+I\left(T_{s} \in(1,6]\right)+I\left(T_{s} \in(6,12]\right)=1$, so that in the case $(22)$ we can only estimate

$$
\begin{aligned}
& P\left[T_{c} \in(12, \infty) \mid T_{s} \in(0,1], T_{s} \in(1,6]\right] \\
& =F\left(\beta_{3,0}+\beta_{3,1} I\left(T_{s} \in(0,1]\right)+\beta_{3,2} I\left(T_{s} \in(1,6]\right)\right)
\end{aligned}
$$

Note that we do not need to worry about misspecification of these Logit models, because the explanatory variables involved are mutually exclusive dummy variables. Therefore, the hypothesis (17) is equivalent to the hypothesis $\beta_{1,1}=0$ in (20), the hypothesis (18) is equivalent to the hypothesis $\beta_{2,1}=\beta_{2,2}=0$ in (21), and the hypothesis (19) is equivalent to the hypothesis $\beta_{3,1}=\beta_{3,2}=\beta_{3,3}=0$ in $(22)$ if $G=1$, and to the hypothesis $\beta_{3,1}=\beta_{3,2}=0$ in (23) if $G=0$. The estimation and test results are presented in Tables A.3 and A.4. In all cases the null hypothesis is not rejected by the Wald test (or squared t test in the case $i=1$ ) at any conventional significance level! 
Table A.3. Logit results for (20)-(22)/(23)

Treatment group $(G=1)$

\begin{tabular}{|r|r|r|r|r|r|}
\hline$i$ & $\beta_{i, 0}$ & $\beta_{i, 1}$ & $\beta_{i, 2}$ & $\beta_{i, 3}$ & Wald test \\
\hline & (t-value) & (t-value) & (t-value) & (t-value) & (p-value) \\
\hline 1 & -1.2809338 & -0.0391111 & & & 0.0225 \\
\hline & $(-7.17)$ & $(-0.15)$ & & & $(0.88076)$ \\
\hline 2 & -1.5040774 & -0.0606246 & 0.1094842 & & 0.88076 \\
\hline & $(-3.33)$ & $(-0.12)$ & $(0.22)$ & & $(0.83261)$ \\
\hline 3 & 0.4054651 & -0.1335314 & -0.2595112 & 0.1823216 & 1.19 \\
\hline & $(0.44)$ & $(-0.14)$ & $(-0.28)$ & $(0.18)$ & $(0.75601)$ \\
\hline
\end{tabular}

Table A.4 . Logit results for (20)-(22)/(23)

Control group $(G=0)$

\begin{tabular}{|r|r|r|r|r|}
\hline$i$ & $\beta_{i, 0}$ & $\beta_{i, 1}$ & $\beta_{i, 2}$ & Wald test \\
\hline & (t-value) & (t-value) & (t-value) & $(\mathrm{p}$-value) \\
\hline 1 & -1.2992830 & 0.0216225 & & 0.0025 \\
\hline & $(-3.99)$ & $(0.05)$ & & $(0.96012)$ \\
\hline 2 & -1.6094379 & -0.1973594 & 0.0930904 & 0.35 \\
\hline & $(-1.47)$ & $(-0.17)$ & $(0.08)$ & $(0.83801)$ \\
\hline 3 & -0.6931472 & 1.1093076 & 1.1826954 & 1.69 \\
\hline & $(-0.80)$ & $(1.24)$ & $(1.29)$ & $(0.42906)$ \\
\hline
\end{tabular}


Table A.5. Job search: Model 1

\begin{tabular}{|l|r|r|l|}
\hline Covariates & Estimates & t-val. & \\
\hline$A G E$ & 0.001374 & 0.141 & $*$ \\
\hline$A G E 1 A R R$ & 0.011526 & 0.964 & $*$ \\
\hline$D R U G S$ & -0.060380 & -0.526 & $*$ \\
\hline$W H I T E$ & 0.128538 & 1.051 & $*$ \\
\hline$M A L E$ & -0.206205 & -1.258 & $*$ \\
\hline$C H I C A G O$ & -1.188883 & -7.057 & \\
\hline SANDIEGO & -0.353766 & -2.454 & \\
\hline$E D U C \_L$ & -0.261975 & -1.393 & $*$ \\
\hline$E D U C \_H$ & -0.094193 & -0.592 & $*$ \\
\hline Parameters & & & \\
\hline$\alpha_{1}$ & 1.139577 & 2.788 & \\
\hline$\alpha_{2}$ & 0.806235 & 2.577 & \\
\hline$\alpha_{3}$ & 1.082720 & 2.186 & \\
\hline Log-likelihood: & -417.622 & & \\
\hline Sample size: & 503 & & \\
\hline
\end{tabular}

\subsection{Job search model specification}

The initial maximum likelihood results for job search are presented in Table A.5. Recall that the $\alpha$ 's are the parameters of the integrated baseline hazard (9).

The Wald test of the hypothesis that the coefficients of the covariates in Table A.5 indicated by an asterix (*) are jointly zero has p-value 0.45137. The Wald test of the null hypothesis $\alpha_{1}=\alpha_{2}=\alpha_{3}$ has p-value 0.10356 , so that the null hypothesis involved cannot be rejected at the $10 \%$ significance level. Recall that the latter hypothesis implies that the baseline hazard is constant. However, for the time being we will not implement the restriction $\alpha_{1}=\alpha_{2}=\alpha_{3}$. First, we will get rid of the insignificant covariates. The results are presented in Table A.6.

The null hypothesis $\alpha_{1}=\alpha_{2}=\alpha_{3}$ is now rejected: the Wald test involved has p-value 0.01131. On the other hand, the null hypothesis $\alpha_{2}=\alpha_{3}$ is accepted: The Wald test involved has p-value 0.39498. The latter result indicates that the baseline hazard is non-increasing. This suggests to specify a Weibull baseline hazard. The estimation results involved are presented in Table 4. 
Table A.6. Job search: Model 2

\begin{tabular}{|l|r|r|}
\hline Covariates & Estimates & t-val. \\
\hline CHICAGO & -1.211832 & -7.739 \\
\hline SANDIEGO & -0.326150 & -2.303 \\
\hline Parameters & & \\
\hline$\alpha_{1}$ & 1.185860 & 10.711 \\
\hline$\alpha_{2}$ & 0.847022 & 6.014 \\
\hline$\alpha_{3}$ & 1.061613 & 3.719 \\
\hline Log-likelihood: & -420.811 & \\
\hline Sample size: & 503 & \\
\hline
\end{tabular}

As a double-check whether the model can be reduced from the initial model in Table A.5 to the model in Table 4 we have conducted the likelihoodratio test: The LR test involved has p-value 0.35230 , hence the hypothesis cannot be rejected at any conventional significance level. Moreover, the t-test statistic of the null hypothesis $\alpha_{2, s}=1$ has value -2.091 , which is borderline significant at the $5 \%$ level for the two-sided t-test, and significant for the left-sided t-test (the corresponding left-sided p-value is 0.01826). Since it is implausible that the "hazard" of finding a job increases with the job search duration, the left-sided result prevails.

\subsection{Recidivism of the control group}

The initial maximum likelihood results are presented in Table A.7.

The covariate $A G E$ is borderline significant at the $5 \%$ level; all the other covariates are insignificant at any conventional significance level. The Wald test that all the coefficients of the covariates (including the one for $A G E$ ) are zero has p-value 0.32881 , hence the null hypothesis that $T_{c}$ does not depend on covariates cannot be rejected at any conventional significance level. Moreover, the Wald test of the null hypothesis $\alpha_{1}=\alpha_{2}=\alpha_{3}$ has p-value 0.80083 , and therefore cannot be rejected at any conventional significance level. Recall that this hypothesis is equivalent to the hypothesis that $\Lambda_{c}(t)=$ $\alpha_{1} t$. Thus, the distribution of $T_{c}$ for the control group is exponential, without covariates!

The LR test that the model in Table A.7 can be reduced to the exponential model in Table 5 has p-value 0.59809 , hence the latter cannot be rejected at any conventional significance level. Therefore, we will adopt the 
Table A.7. Recidivism of the control group: Initial model

\begin{tabular}{|l|r|r|}
\hline Covariates & Estimates & \multicolumn{1}{c|}{ t-val. } \\
\hline$A G E$ & -0.057819 & -2.098 \\
\hline$A G E 1 A R R$ & -0.061837 & -1.716 \\
\hline$D R U G S$ & 0.232762 & 0.733 \\
\hline$W H I T E$ & -0.012282 & -0.036 \\
\hline$M A L E$ & -0.290917 & -0.721 \\
\hline$C H I C A G O$ & 0.287844 & 0.725 \\
\hline SANDIEGO & 0.069299 & 0.165 \\
\hline$E D U C_{-} L$ & -0.103330 & -0.206 \\
\hline$E D U C_{-} H$ & 0.748567 & 1.741 \\
\hline Parameters: & & \\
\hline$\alpha_{1}$ & 0.366003 & 0.906 \\
\hline$\alpha_{2}$ & 0.609465 & 0.957 \\
\hline$\alpha_{3}$ & 0.493359 & 1.010 \\
\hline Log-likelihood: & -134.728 & \\
\hline Sample size: & 134 & \\
\hline
\end{tabular}

exponential model (11) for the recidivism of the control group.

\subsection{Joint maximum likelihood results}

The initial maximum likelihood estimation results are presented in Table A.8, for recidivism only.

The parameters in Table A.8 indicated by an asterix $\left(^{*}\right)$ are jointly insignificant: The p-value of the Wald test involved is 0.42136 . Therefore, in the next estimation round these covariates have been removed. See Table A.9.

The Wald test that only $A G E$ matters for recidivism yields p-value 0.03464 , hence this hypothesis is rejected at the $5 \%$ significance level. The Wald test that the coefficients of the two location dummy variables are equal has p-value 0.53307 , which indicates that we may replace these dummy variables by the dummy variable BOSTON $=1-C H I C A G O-S A N D I E G O$. Moreover, the test of the same hypothesis, jointly with the hypothesis that the coefficient of $E D U C_{-} L$ is zero, has p-value 0.20804 . Therefore, we have re-estimated the model without the education dummy, and with the location 
Table A.8. Recidivism: Model 1

\begin{tabular}{|l|r|r|l|}
\hline Covariates & Estimates & t-val. & \\
\hline$D R U G S$ & -0.217296 & -1.027 & $*$ \\
\hline$C H I C A G O$ & -0.523601 & -2.073 & \\
\hline SANDIEGO & -0.461512 & -1.926 & \\
\hline$W H I T E$ & -0.278290 & -1.332 & $*$ \\
\hline$M A L E$ & -0.050078 & -0.154 & $*$ \\
\hline$E D U C \_L$ & 0.576838 & 1.874 & \\
\hline$E D U C \_H$ & -0.330336 & -0.939 & $*$ \\
\hline$A G E$ & -0.040221 & -2.200 & \\
\hline$A G E 1$ ARR & -0.030686 & -1.292 & $*$ \\
\hline 1 & 2.245037 & 3.226 & \\
\hline Parameter & Estimate & t-val. & \\
\hline$\alpha_{c}$ & 0.041529 & 7.672 & \\
\hline Log-Likelihood: & -842.896 & & \\
\hline Sample size: & 503 & & \\
\hline
\end{tabular}

Table A.9. Recidivism: Model 2

\begin{tabular}{|l|r|r|}
\hline Covariates & Estimates & t-val. \\
\hline$C H I C A G O$ & -0.301132 & -1.350 \\
\hline$S A N D I E G O$ & -0.460476 & -2.030 \\
\hline$E D U C \_L$ & 0.487441 & 1.639 \\
\hline$A G E$ & -0.047794 & -2.870 \\
\hline 1 & 1.707907 & 3.581 \\
\hline Parameter & Estimate & t-val. \\
\hline$\alpha_{c}$ & 0.040407 & 7.550 \\
\hline Log-Likelihood: & -845.992 & \\
\hline Sample size: & 503 & \\
\hline
\end{tabular}


dummies replaced by the dummy variable BOSTON. See Table 6 .

As a double-check we have conducted the LR test that the initial model in Table A.8 can be reduced to the model in Table 6 . The p-value of the test is 0.25816 .

\section{References}

Abbring JH, Van den Berg GJ (2003): The non-parametric identification of treatment effects in duration models, Econometrica, 71, 1491-1517.

Abbring JH, Van den Berg GJ, Van Ours JC (2005): The effect of unemployment insurance sanctions on the transition rate from unemployment to employment, Economic Journal, 115, 602-630.

Bierens HJ (2006): EasyReg International, Pennsylvania State University. http://econ.la.psu.edu/ hbierens/EASYREG.HTM.

Bierens HJ (2007): Semi-nonparametric interval-censored mixed proportional hazard models: Identification and consistency results, Econometric Theory, forthcoming. http://econ.la.psu.edu/ hbierens/SNPMPHM.PDF.

Bierens HJ, Carvalho JR (2007): Semi-nonparametric competing risks analysis of recidivism, Journal of Applied Econometrics, 22, 971-993. http:// econ.la.psu.edu/ hbierens/RECIDIVISM2.PDF.

Bloom HS (1984): Accounting for no-shows in experimental evaluation design, Evaluation Review, 8, 225-246.

Bloom D (2006): Employment-focused programs for ex-prisoners. What have we learned, what are we learning, and where should we go from here? Michigan Disability Rights Coalition. http://www.mdrc.org/publications /435/full.pdf.

Bureau of Justice Statistics (1994): Recidivism of Prisoners Released in 1994.

Beck AJ, Shipley BE (1989): Recidivism of prisoners released in 1983, Special report, Bureau of Justice Statistics.

Carvalho JR, Bierens HJ (2007): Conditional treatment and its effect on recidivism, Brazilian Review of Econometrics, 27, 53-84. http://econ.la.psu .edu/ hbierens/CONDTREAT.PDF.

Devine T, Kiefer N (1991): Empirical Labor Economics: The Search Approach. Oxford University Press, New York.

Eberwein C, Ham J, Lalonde R (1997): The impact of being offered and receiving classroom training on the employment histories of disadvantaged 
women: Evidence from experimental data, Review of Economic Studies, 64, 655682.

Fagan J, Freeman R (1999): Crime and work, Crime and Justice, 25, 225-290.

Farrington DP, Welsh BC (2005): Randomized experiments in criminology: what have we learned in the last two decades? Journal of Experimental Criminology, 1, 9-38.

Freeman R (1999): Economics of crime. The Handbook of Labor Economics, Vol 3C, North Holland, Amsterdam.

Freeman R (2003): Can we close the revolving door?: Recidivism versus employment of ex-offenders in the US., Urban Institute Reentry Round Table, New York University Law School.

Gendreau P, Little T, Goggin C (1996): A meta-analysis of the predictors of adult offender recidivism: What works!, Criminology, 34, 575607.

Harer MD (1994): Recidivism among federal prisoners released in 1987, Journal of Correctional Education, 46, 98-127.

Heckman J, Lalonde RJ, Smith JA (1999): The economics and econometrics of active labor market programs, Handbook of Labor Economics, Vol. 3A, Elsevier Science, Amsterdam, 1865-2097.

Heckman J, Smith J, Taber C (1998): Accounting for dropouts in evaluations of social programs, The Review of Economics and Statistics, 80, 1-14.

Maltz MD (1984): Recidivism: Quantitative Studies in Social Sciences. Academic Press, Orlando, FL.

Milkman R (2001): Employment services for ex-offenders, 1981-1984: Boston, Chicago, and San Diego, Discussion Paper 8619, ICPSR.

Milkman R, Timrots A, Peyser A, Toborg M, Yezer BGA., Carpenter L, Landson N (1985): Employment services for ex-offenders field test, Discussion paper, The Lazar Institute.

Pissarides CA (2000): Equilibrium Unemployment Theory (Second edition). MIT Press, Cambridge, MA.

Sampson RJ, Laub JH (1997): A life-course theory of cumulative disadvantage and the stability of delinquency, Advances in Criminological Theory, $7,133-161$.

Seiter RP, Kadela KR (2003): Prisoner reentry: what works, what does not, and what is promising, Crime $\mathcal{E}$ Delinquency, 49,360-388.

Schmidt P, Witte AD (1988): Predicting Recidivism Using Survival Models: Research in Criminology. Springer-Verlag, Berlin. 
Timrots A (1985): An evaluation of employment services programs for ex-offenders, Masters thesis, University of Maryland, College Park.

Uggen C (2000): Work as a turning point in the life course of criminals: A duration model of age, employment and recidivism, American Sociological Review, 65, 529-546.

Van den Berg GJ (1999): Empirical inference with equilibrium search models of the labor market, The Economic Journal, 109, 283-306.

Van den Berg GJ (2000): Duration models: Specification, identification, and multiple durations, Handbook of Econometrics, Vol. V, North Holland, Amsterdam.

Van den Berg GJ, Van der Klaauw B, Van Ours JC (2004): Punitive sanctions and the transition rate from welfare to work, Journal of Labor Economics, 22, 211-241.

Visher CA, Winterfield L, Coggeshall MB (2005): Ex-offender employment programs and recidivism: a meta-analysis, Journal of Experimental Criminology, 1, 295-316.

Western B (2002): The impact of incarceration on wage mobility and inequality, American Sociological Review, 67, 526-546. 